\title{
Radiological Survey of the Concentration Department in State Company of Phosphate
}

\author{
Alaa Fadhil Hashim, Zaki Abdul Jabbar, Haider Ahmad Hassan, Ali Khadum Aial \\ Radiation \& Nuclear Safety Directorate, Ministry of Science and Technology, Baghdad, Iraq \\ Email address: \\ Hashimalaa75@gmail.com (A. F. Hashim), zeki_alqaisy@yahoo.com (Z. A. Jabar) \\ To cite this article: \\ Alaa Fadhil Hashim, Zaki Abdul Jabbar, Haider Ahmad Hassan, Ali Khadum Aial. Radiological Survey of the Concentration Department in \\ State Company of Phosphate. Frontiers in Environmental Microbiology. Vol. 6, No. 1, 2020, pp. 1-4. doi: 10.11648/j.fem.20200601.11
}

Received: December 31, 2019; Accepted: January 7, 2020; Published: January 17, 2020

\begin{abstract}
The purpose of this research is to conduct a radiological survey of the crushing, milling, screening and conveyor unit of raw materials in the al-Qa'im fertilizer plant/General Phosphate Company, in order to calculate the absorbed doses of the workers in these places as well as the work hazards. As the raw materials in the phosphate fertilizer industry are extracted from the ground, Certainly contains radioisotopes such as the series of decay of uranium, thorium and potassium, which is the main cause of radiation activity in raw materials and the results of the dose absorbed to the workers in the unit of grinding, cracking and screening, And the conveyor belt for raw materials is $(0.34,0.38) \mathrm{mSv} / \mathrm{y}$ respectively, which is less than the internationally allowed limits $(1 \mathrm{msv} / \mathrm{y})$ and the risk of working on working persons $\left(1.7 \times 10^{-5}, 1.9 \times 10^{-5}\right)$ For crushing and crushing unit and belt conveyor unit, respectively, within the limits of internationally licensed $10^{-5}$.
\end{abstract}

Keywords: NORM, Phosphate Rocks, Radiation Contamination

\section{Introduction}

Radioactivity and external exposure associated with gamma radiation depend primarily on the nature of the geological and geological characteristics that vary and vary from one region to another in the world $[1,2,4]$. Radioactivity is the emission of alpha $(\alpha)$ and beta $(\beta)$ particles as well as gamma $(\gamma)$ radiation from the unstable isotopes. Most minerals, that contain potassium, uranium and thorium, are radioactive $[3,5,6]$. Long-live radioactive elements such as uranium $\left({ }^{238} \mathrm{U}\right)$, thorium $\left({ }^{232} \mathrm{Th}\right)$ and potassium $\left({ }^{40} \mathrm{~K}\right)$ and any of their decay products, such as radium and radon are examples of naturally occurring radioactive materials (NORM) [5-9]. Mining like many other industries can cause environmental impact [8-10]. However, for the NORM (Naturally Occurring Radioactive Material) industries, to the impact caused by conventional ways is added the radiological impact. Phosphates are used extensively, as a source of phosphorous for fertilizers and for manufacturing phosphoric acid and gypsum. Phosphate ores typically contain about $1500 \mathrm{~Bq} / \mathrm{kg}$ of uranium and radium, although some phosphates contain up to $20,000 \mathrm{~Bq} / \mathrm{kg}$ of $\mathrm{U}_{3} \mathrm{O}_{8}$ [11]. Phosphate rocks with potassium ores and nitrogen compounds are among the main components used to produce fertilizers. Compounds are found to be important for plant growth. Phosphate rocks are used for the production of chemical fertilizers after phosphate extraction $[4,12]$. The presence of radioactive isotopes of ${ }^{238} \mathrm{U},{ }^{232}$ Thand ${ }^{40} \mathrm{~K}$ In phosphates, the specific activity of radionuclides in phosphates is based on industrial output, which depends on their concentrations in the raw materials of phosphates (phosphate rock and phosphoric acid), as well as on the process of chemical separation during production processes Phosphate fertilizers $[8,11,13]$.

The Iraqi State Company for Phosphate is located at AlQaim city with a coordinates (N 34.33465, E 41.18273). It is located at $150 \mathrm{~km}$ northeast of Akashat. The design capacity of the plant is one million tons of phosphate fertilizer annually. Phosphate rocks are transported from Akashat by the railway built for this purpose. Iraq have a huge amount of phosphate reserve more than 10000 MT which is located in the Western Desert of Iraq, Al-Anbar Governorate, Akashat site, $120 \mathrm{~km}$ southwest of the Euphrates river. These are among the largest phosphate reserve in the world.

The amount of phosphogypsum waste produced by the phosphate industry is approximated to $20 \%$ of the ore 
material while the Iraqi reserve of ore phosphate is approximated to 4 billion tons. The drying and grinding stage produced radioactive material and released to the air in the form of fine powder, each ton of phosphate treated release about $100 \mathrm{~Bq}$ of uranium ${ }^{238} \mathrm{U}$, these contaminated air and soil of the surrounding environment [10-14].

Contaminated area with naturally occurring radioactive material (NORM) is produced from uncontrolled disposal of phosphogypsum waste in the surrounding environment or fine powder release to the air produced from the drying and grinding stage is considered as a real big problem in Iraq, which causes exposure and contamination of worker and environment $[14,15]$. The excessive use of these fertilizers contributes significantly to the increase in the radiation activity of the soil and thus increase the radiation exposure rates in all the production stages that the phosphate fertilizers undergo from the industrial processes such as mining and the transfer of phosphate fertilizers and the production of fertilizers and the spread of these fertilizers in the soil, water and air, Contributes to the high exposure of workers, the public and the environment $[4,7$, $10]$.

The aim of the research is to detect the radiation contamination rates of the concentration unit and surrounding areas in the General Phosphate Company in Qaim to take the necessary measures to prevent and reduce radiation contamination in the case of high concentration of radiation activity, using portable survey meter.

\section{Materials and Methods}

\subsection{RadEye Model PRD}

RadEye model PRD (Alarming personal radiation detector, Thermo Scientific, Germany) was used in the field for monitoring gamma radiation dose rates [16]. RadEye model PRD is a highly sensitive device used to measure gamma radiation in terms of counts per second (cps), ambient equivalent dose rate in microsevert per hour $(\mu \mathrm{Sv} / \mathrm{h})$ and the accumulated ambient equivalent dose (in $\mu \mathrm{Sv}$ ). The RadEye model PRD incorporates a highly sensitive NaI (TI) scintillation detector which is equipped with alow radiation levels. The detection for gamma radiation dose rate range from $0.01 \mu \mathrm{Sv} / \mathrm{h}$ to $250 \mu \mathrm{Sv} / \mathrm{h}$. The selection of RadEye model PRD over other available radiation detector is primarily based on the RadEye PRD's ability to detect low energy gamma radiation, which comprises the majority of the gamma radiation from the radionuclides of the conserved in the studies areas.

\subsection{Ludlum (Ludlum Measurements, Inc. (LMI) Designs and Manufactures Radiation Detection Instruments and Technologies, Sweetwater, Texas, USA)}

This device is a multipurpose survey, gross counting, digital ratemeter with a built-in scaler that provides timed counts over a user specified period. The instrument additionally includes an External: Supports GM \& Scintillation Detectors, Alpha, Beta, and Gamma surveying Display Range $(0.000 \mu \mathrm{Sv} / \mathrm{h}$ to $9999 \mathrm{~Sv} / \mathrm{h}$ and $0 \mathrm{cps}$ to $100 \mathrm{kcps}$ ).

Measurements of levels of exposure and radiation contamination were made on the ground and by mobile device Radeye (the Measurements of the levels of radiation contamination at a height of $3 \mathrm{~cm}$ and The Measurements of the levels of radiation exposure at a height of $1 \mathrm{~m}$ ) in Crushing, grinding and screening units, conveyor belts for silo and the residential complex, which was considered a radiological background area.

The silo was divided to grids, each grid with an area $\left(1 \mathrm{~m}^{2}\right)$ inside the silo. The points were ( 21 points) inside the silo for Crushing, grinding and screening units, conveyor belts for silo and the residential complex and these points are represented by (x, y) axes. The Measurements were adopted to calculate the received dose and risk rates inside at $(1 \mathrm{~m})$ height for each point because it is the effective dose on the human.

\section{Calculations \& Discussion}

Measurements of radiation levels of the residential complex were carried out and the Measurements ranged from (0.02-0.05 $\mu \mathrm{Sv} / \mathrm{h}$ ) with the rate of Radiation background $0.03 \mu \mathrm{Sv} / \mathrm{h}$ by RadEye and the Measurements of levels of radiation contamination ranged from 11-14 cps with the rate of Radiation background is $12 \mathrm{cps}$, the Measurements of the residential complex are considered as a radiological background area.

Measurements of levels of radiation exposure ranged from (0.20-0.23 $\mu \mathrm{Sv} / \mathrm{h}),(0.24-0.26 \mu \mathrm{Sv} / \mathrm{h})$ for crushing, grinding and screening units and conveyor belts respectively, Measurements of levels of radiation contamination ranged from (89-111 cps), (183-213 cps) for Crushing, grinding and screening units and conveyor belts respectively.

The rate of radiation exposure for Crushing, grinding and screening units and conveyor belts $(0.22 \mu \mathrm{Sv} / \mathrm{h})$ and $(0.25$ $\mu \mathrm{Sv} / \mathrm{h})$ respectively, these Measurements more than seven times of the rate of the background radiation $(0.03 \mu \mathrm{Sv} / \mathrm{h})$. The rate of radiation contamination for Crushing, grinding and screening units and conveyor belts (96 cps) and (192.3 cps) respectively, these readings more than eight and seventeen times of the rate of the background radiation $(12 \mathrm{cps})$.

Table 1. Measurement of levels of radiation exposure and contamination.

\begin{tabular}{|c|c|c|c|c|c|}
\hline No. & Name of place & $\mathbf{X}$ & $\mathbf{Y}$ & RadEye $\mu S v / h$ & Ludlum C/s \\
\hline 1 & \multirow{7}{*}{$\begin{array}{l}\text { The residential complex (radiological background } \\
\text { area) }\end{array}$} & \multirow{7}{*}{3433491} & \multirow{7}{*}{4119663} & 0.02 & 10 \\
\hline 2 & & & & 0.02 & 12 \\
\hline 3 & & & & 0.02 & 13 \\
\hline 4 & & & & 0.05 & 12 \\
\hline 5 & & & & 0.04 & 11 \\
\hline 6 & & & & 0.03 & 14 \\
\hline 7 & & & & 0.03 & 12 \\
\hline
\end{tabular}




\begin{tabular}{|c|c|c|c|c|c|}
\hline No. & Name of place & $\mathbf{X}$ & $\mathbf{Y}$ & RadEye $\mu \mathrm{Sv} / \mathrm{h}$ & Ludlum C/s \\
\hline & Average & & & 0.03 & 12 \\
\hline 8 & & & & 0.22 & 111 \\
\hline 9 & & & & 0.21 & 95 \\
\hline 10 & & & & 0.21 & 100 \\
\hline 11 & Crushing, Grinding and Screening units & 3431617 & 4117819 & 0.22 & 95 \\
\hline 12 & & & & 0.20 & 89 \\
\hline 13 & & & & 0.23 & 89 \\
\hline \multirow[t]{2}{*}{14} & & & & 0.23 & 92 \\
\hline & Average & & & 0.22 & 96 \\
\hline 15 & & & & 0.25 & 213 \\
\hline 16 & & & & 0.25 & 202 \\
\hline 17 & & & & 0.26 & 186 \\
\hline 18 & Conveyor Belts & 3431569 & 4117698 & 0.25 & 191 \\
\hline 19 & & & & 0.24 & 187 \\
\hline 20 & & & & 0.26 & 184 \\
\hline \multirow[t]{2}{*}{21} & & & & 0.25 & 183 \\
\hline & Average & & & 0.25 & 192.3 \\
\hline
\end{tabular}

The received dose per year of the workers on $1 \mathrm{~m}$ height in the Crushing, Grinding and Screening units calculated by following:

a. Dose received $=0.22 \mu \mathrm{Sv} / \mathrm{h} \times 1 \mathrm{~h} \times 10^{-3}$

$$
=22 \times 10^{-5} \mathrm{mSv} / \mathrm{h}
$$

b. By assumed the worker works ( 8 hour/day) with (4 day/week)

Number of working hours per the year

$$
\begin{aligned}
& =8 \mathrm{~h} / \mathrm{d} \times 4 \mathrm{~d} / \mathrm{w} \times 4 \mathrm{w} / \mathrm{m} \times 12 \mathrm{~m} / \mathrm{y} \\
& =1536 \mathrm{~h} / \mathrm{y}
\end{aligned}
$$

c. Rate of dose received per the year

$$
\begin{aligned}
& =22 \times 10^{-5} \mathrm{mSv} / \mathrm{h} \times 1536 \mathrm{~h} / \mathrm{y} \\
& =0.34 \mathrm{mSv} / \mathrm{y}
\end{aligned}
$$

Also, the received dose per year of the workers on $1 \mathrm{~m}$ height during ( 8 hour working) in the Conveyor Belts is equal to $(0.38 \mathrm{mSv} / \mathrm{y})$. [17]

The risk assessment is the systematic identification of potential hazards in the workplace as a first step to controlling the possible risk involved. The risk of developing a fatal cancer ( $\mathrm{Rf}$ ) as a result of radiation exposure is estimated as below:-

$$
\mathrm{R}_{\mathrm{f}}=\mathrm{D} \times \mathrm{RF} \ldots
$$

Where $\mathrm{D}$ is the dose to an exposed individual or exposed population, and RF is the risk factor.

Based on an occupational risk factor of $0.05 \mathrm{~Sv}^{-1}$ (risk factor to injury with fatal cancer) [17].

Risk for one person $=$ dose rate $\times$ number of year $\times$ risk factor

$$
=0.34 \mathrm{mSv} / \mathrm{y} \times 1 \mathrm{y} \times 0.05 \mathrm{~Sv}^{-1} \times 10^{-3}
$$

$=1.7 \times 10^{-5}$ (in the Crushing, Grinding and Screening units).

Also, the risk for one person in the Conveyor Belts is equal to $\left(1.9 \times 10^{-5}\right)$.

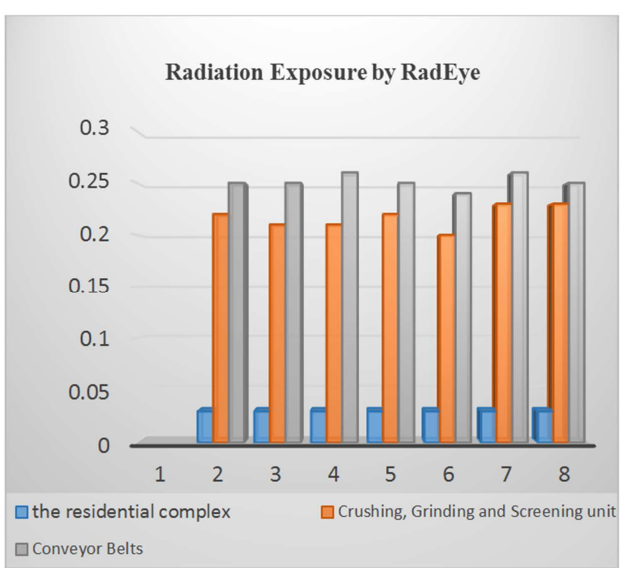

Figure 1. Measurements of levels of radiation exposure by RadEye in the residential complex, crushing, grinding and screening units and conveyor belts.

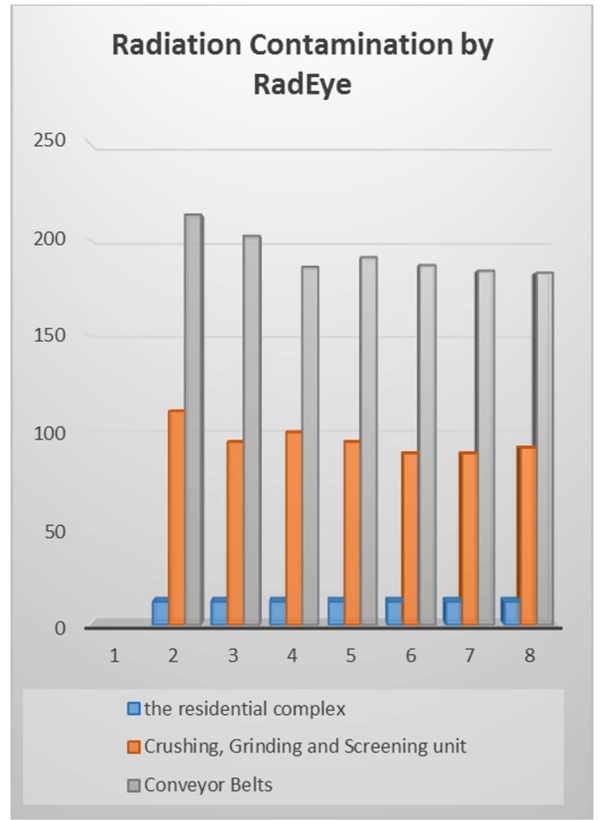

Figure 2. Measurements of levels of radiation contamination by RadEye in the residential complex, crushing, grinding and screening units and conveyor belts. 


\section{Conclusion}

The total annual dose limit and approved by the International Commission on Radiological Protection (ICRP) in Publication 60 and the International Atomic Energy Agency (IAEA) in Basic Safety Standards (Safety Series No. $15)$ for each year is $(1 \mathrm{mSv})$, the dose rate received in the Crushing, Grinding and Screening units was $(0.34 \mathrm{mSv} / \mathrm{y})$, it is within the dose limits $(1 \mathrm{mSv})$, also the dose rate received the Conveyor Belts was $(0.38 \mathrm{mSv} / \mathrm{y})$ are within the doses limits $(1 \mathrm{mSv})$.

The risk for one person is $\left(1.7 \times 10^{-5}\right)$ in the Crushing, Grinding and Screening units, It is within the international limits permitted and approved by the International Commission on Radiological Protection (ICRP) in Publication 60 and the International Atomic Energy Agency (IAEA) in Specific Safety RequirementsNo. SSR-5 which is $\left(10^{-5}\right.$ per year) $[18,19]$. Also the risk in the Conveyor Belts was is $\left(1.9 \times 10^{-5}\right)$, it is within the international limits permitted $\left(10^{-5}\right)$.

The reason for the increase in readings more than the radiation background is about eighty times due to the presence of phosphate ore and this indicates the presence of Naturally Occurring Radioactive Material (NORM), such as uranium $\left({ }^{238} \mathrm{U}\right)$, thorium $\left({ }^{232} \mathrm{Th}\right)$ and potassium $\left({ }^{40} \mathrm{~K}\right)$. To reduce the risk of internal exposure to workers must wear protective glasses, special suits and the particulate respirator is preventing about $95 \%$ from the entered dust to the respiratory system.

\section{References}

[1] Kerur, B. R., Rajeshwari, T., Sharanabsappa, Anil Kumar, S., Narayan, K., Rekha, A., Haumaiah, B., 2010, Radioactivity levels in North Karnataka, India. Indian Journal of Pure\& Applied Physics. 48, 809-812.

[2] Lambert, R., Grant, C., Sauve, C., 2007. Cadmium and zinc in soil solution extracts following the application of phosphate fertilizers. Sci. Total Environ. 378, 293-305.

[3] Hofman, J., Leicht, R., Wingender, H. J., Worner, J., 2000. Natural radionuclide concentrations in materials processed in the chemical industry and the related radiological impact. European Commission Report EUR-19264, Directorate General Environment.

[4] Podbiera-Matysik, K., Gorazda, K., Wzorek, Z., Potential management of waste phosphogypsum with particular focus on recovery of rare earth metals. Pol. J. of Chem. Technol. 17: 55-61.

[5] Yang J., Liu W., Zhang L., Xiao B. 2009. Preparation of loadbearing building materials from autoclaved phosphogypsum. Const. Build. Mat. 23, 687-693.
[6] Rutherford P. M., Dudas M. J., Samek R. A. 1994. Environmental impacts of phosphogypsum. Sci. Total Environ $149(1-2), 1-38$.

[7] Tayibi H., Choura M., López F. A., Alguacil J. A., LópezDelgado A. 2009. Environmental impact and management of phosphogypsum (Review). J. Environ. Manage. 90, 23772386.

[8] Tayibi H., N. Navarro, A. Lopez-Delgado, F. J. Alguacil and F. A. Lopez. 2009. The Radiological Impact and Restriction on Phosphogypsum Waste Applications. Spanish National Conference on Advances in Martials Recycling and Eco. 7174.

[9] Yang M., Qain J., Pang Y. 2008. Activation of fly ash-lime system using calcinedphosphogypsum. Const. Build. Mat. 22, 1004-1008.

[10] Taher M. A. 2007. Influence of thermally treated phosphogypsum on the properties of Portland slag cement, Resour. Conserv. Recycl. 52 (1), 28-38.

[11] Mas J. L., San Miguel E. G., Bolivar J. P., Vaca F., PerezMoreno J. P. 2006. An assay on the effect of preliminary restoration tasks applied to a large TENORM wastes disposal in the south-west of Spain. Sci. Total Environ. 364, 55-66.

[12] El Afifi E. M., Hilal M. A., Attallah M. F., El-Reefy S. A. 2009. Characterization of phosphogypsum wastes associated with phosphoric acid and fertilizers production. J. Environ Radioact. 100, 407-412.

[13] Burnett W. C., Schultz M. K., Carter D. H. 1996. Radionuclide flow during the conversion of phosphogypsum to ammonium sulphate. J. Environ Radioact. 32 (1-2), 33-51.

[14] Mansoor, Z. A., Ahmed, H., Abed, A. H., Abdullah, H. H., 2015 "Assessment of Radioactivity for Phosphogypsum in State Company for Phosphate", Proceeding of $14^{\text {th }}$ Arab Conference on the Peaceful Uses of Atomic Energy, CairoEgypt, 918-923.

[15] AL-Jasim Ali Kareem, Al-Draisawi Abbas Neamah, AlTameemiNabeelHashim, 2017. Radiological Risk Assessment for French Silo at Al-Tuwaitha Nuclear Research Site. International Journal of Clinical Oncology and Cancer Research. Vol. 2, No. 5, 2017, pp. 99-105.

[16] Thermo scientific, Manual of Alarming Personal Radiation Detector, Rad Eye PRD, DB_057-050322 E.

[17] INTERNATIONAL ATOMIC ENERGY AGENCY (IAEA), Radiation Protection and Safety of Radiation Sources International Basic Safety Standard GSR part 3, Vienna, 2014.

[18] INTERNATIONAL COMMISSION ON RADIOLOGICAL PROTECTION, Publication 60, 1990 Recommendations of the International Commission on Radiological Protection, Annals ICRP 21 (1-3): 1-201, 1991.

[19] INTERNATIONAL ATOMIC ENERGY AGENCY, Specific Safety Requirements No. SSR-5, Disposal of Radioactive Waste, IAEA, Vienna (2011). 